\title{
Behavioral management of headache in children and adolescents
}

\author{
Noemi Faedda ${ }^{1}$, Rita Cerutti ${ }^{2}$, Paola Verdecchia ${ }^{1}$, Daniele Migliorini ${ }^{3}$, Marco Arruda ${ }^{4}$ and Vincenzo Guidetti ${ }^{*}$
}

\begin{abstract}
Headache is the most frequent neurological symptom and the most prevalent pain in children and adolescents, and constitutes a serious health problem that may lead to impairment in several areas. Psychosocial factors, social environment, life events, school and family stressors are all closely related to headaches. A multidisciplinary strategy is fundamental in addressing headache in children and adolescents. Applying such a strategy can lead to reductions in frequency and severity of the pain, improving significantly the quality of life of these children.

It has been demonstrated that behavioral intervention is highly effective, especially in the treatment of paediatric headache, and can enhance or replace pharmacotherapy, with the advantage of eliminating dangerous side effects and or reducing costs. Behavioral interventions appear to maximize long-term therapeutic benefits and improve compliance with pharmacological treatment, which has proven a significant problem with child and adolescent with headache.

The goal of this review is to examine the existing literature on behavioral therapies used to treat headache in children and adolescents, and so provide an up-to-date picture of what behavioral therapy is and what its effectiveness is.
\end{abstract}

Keywords: Headache, Behavioral therapies, Non-pharmacological therapies, Cognitive behavioral therapy, Children, Adolescents

Abbreviations: CBT, Cognitive-behavioral therapy; CM, Chronic migraine; Gl, Guided imagery; MA, Migraine with aura; PMR, Progressive muscle relaxation

\section{Introduction}

Headache affects about $60 \%$ of children and adolescents all over the world. Tension type headache (prevalence of $20-25 \%)$ is the most common cause of primary headache, followed by migraine (prevalence of $8 \%$ ) [1]. From epidemiology, it is clear that the onset of primary headache is often in childhood or adolescence [2] and the prevalence grows with children's age. Research shows that children, adolescents and adults with headache do not seek medical care for their headaches and nearly half never receive a diagnosis [3].

Headache can affect all aspects of a child's functioning. It has been associated with psychiatric illness, such as anxiety and depression, as well as psychosocial problems (e.g. school absences, problematic social interactions)

\footnotetext{
* Correspondence: vincenzo.guidetti@uniroma1.it

${ }^{1}$ Department of Pediatrics and Child and Adolescent Neuropsychiatry,

Sapienza University of Rome, Via dei Sabelli, 108, 00185 Rome, Italy

Full list of author information is available at the end of the article
}

$[4,5]$. Recognizing anxiety, depressive symptoms and other psychiatric disorders should be considered in the clinical assessment of headache patients, especially in children and adolescents, as early identification of these symptoms may lead to improved headache management [6]. Furthermore the comorbidity with affective disorders and psychopathology in general may also enhance suicidal risk in migraine patients, especially in children and adolescent population, with a significant impact on public health [7]. Some studies investigated the gene-environment interaction and other risk factors involved in suicidal behaviour in headache patients $[8,9]$ showing that shared mechanism could be implicated in the pathophysiology of both migraine and affective disorders.

Furthermore an excessive use of medication in children and adolescents, and its association with certain undesirable behaviors or lifestyles, suggest educational initiatives on drug use are an important part of treatment [10]. Some non-pharmacological therapies seem to 
have effects that are similar to those of most drugs used for the prevention of migraine and tension-type headaches. These therapies often do not have dangerous adverse effects and are much less expensive than pharmacological therapies both in children and adolescents than in adults $[11,12]$.

An analysis of Mazzotta et al. [13] about the direct and indirect costs of headache in childhood and adolescence, indicates an overall cost of $€ 18,614.30$ for the treatment of twenty-five patients (7-18 years). The total direct cost is $€ 17,290$, of which $93 \%$ covers visits and diagnostic testing, and the remaining $7 \%$ covers symptomatic or prophylactic pharmacological therapy. The average expense for each patient is $€ 691$.60. In considering the different types of headaches, the study shows that the greatest expense is associated with Migraine with aura (MA) patients ( $€ 802.80$ per patient), followed by chronic migraine $(\mathrm{CM})$ patients ( $€ 760.50$ per patient) and finally headache secondary to sinusitis patients (€692 per patient). The conclusion of the study of Mazzotta et al. [13] is that by combining effectiveness, minimal side effects, and cost savings, behavioral interventions provide a treatment option that can enhance or if necessary, replace pharmacotherapy.

Moreover, medications should generally not be prescribed alone but rather in combination with nonpharmacological therapies [14]. In addition, behavioral therapy help maximize long-term therapeutic benefit and ensure compliance with pharmacological treatment, which has been proven a significant problem with headache patients [15].

\section{Review}

\section{Search strategy and selection criteria}

We included the following search terms "headache" OR "migraine" and related terms, AND "behavioral management", "behavioral treatment", "behavioral therapy", "non-pharmacological treatments", "psychiatric comorbidities", "cognitive-behavioral therapy", "treatment adherence", "psychological intervention", "lifestyle habits" IN "children", "childhood", "child", "adolescents", "adolescence", "young" and entered them into Pubmed databases. We reviewed the reference lists of paper identified and included articles judged as relevant. Highly regarded books published and additional non-peer-reviewed literature were included in this review, identified through a Google search and from citations in several key articles. We did our search between Sept 20, 2015, and June 15, 2016.

\section{What is behavioral therapy?}

Behavioral treatment strategies for pain management have been researched intensively in recent years and are mostly derived from cognitive-behavioral therapy (CBT) [16] (Fig. 1). In migraine treatment, behavioral treatment strategies have in many cases been shown to be as effective as pharmacological treatment [17], not only for headache management, but also to maintain a lifetime response to the headache treatment [15].

The American Academy of Neurology-U.S. Consortium [18] noted that, given the presence of specific factors, behavioral and other non-pharmacological treatment are preferred to pharmacological treatment for migraine headache. These factors are:

- patient preference for non-pharmacological treatments;

- poor tolerance or poor response to pharmaceuticals;

- negative side effects of medication;

- actual or planned pregnancy;

- history of overuse of acute care medication;

- significant stress;

- inadequate ability to cope with stress or pain;

- comorbid psychological disorders [19]

In other words, individuals with clinical depression or anxiety, those with moderate-to-severe headache-related disabilities, those with difficulty managing triggers (including stress) or with other significant psychological issues (e.g., history of abuse/maltreatment), and those that prefer behavioral approaches are all ideal candidates for behavioral intervention [18, 20,21].

The goals of behavioral treatments are to reduce the frequency and severity of pain, increase the patients' control of their headaches, reduce related disabilities and symptoms, and limit reliance on poorly tolerated or unwanted medications [22].

The behavioral approach maximizes adherence to the prescribed headache treatment regimen, and incorporates the assessment of the impact of headache on a the child or adolescent's quality of life, disability, and emotional functioning [23]. Non-adherence to prescribed treatment is an important and widespread behavioral health issue in the management of headache [24]. Poor adherence to prescribed treatment regimens can compromise the efficacy of medical treatments, and the health and quality of life of patients [25].

Behavioral therapy consists of three components [26] (Fig. 2):

1) Treatment adherence;

2) Adjustment of lifestyle management;

3) Psychological intervention.

\section{Treatment adherence}

The first component involves educating the patient and his or her parents about the importance of complying with the assigned treatment, and identifying factors may limit the effectiveness of the plan. Several studies 


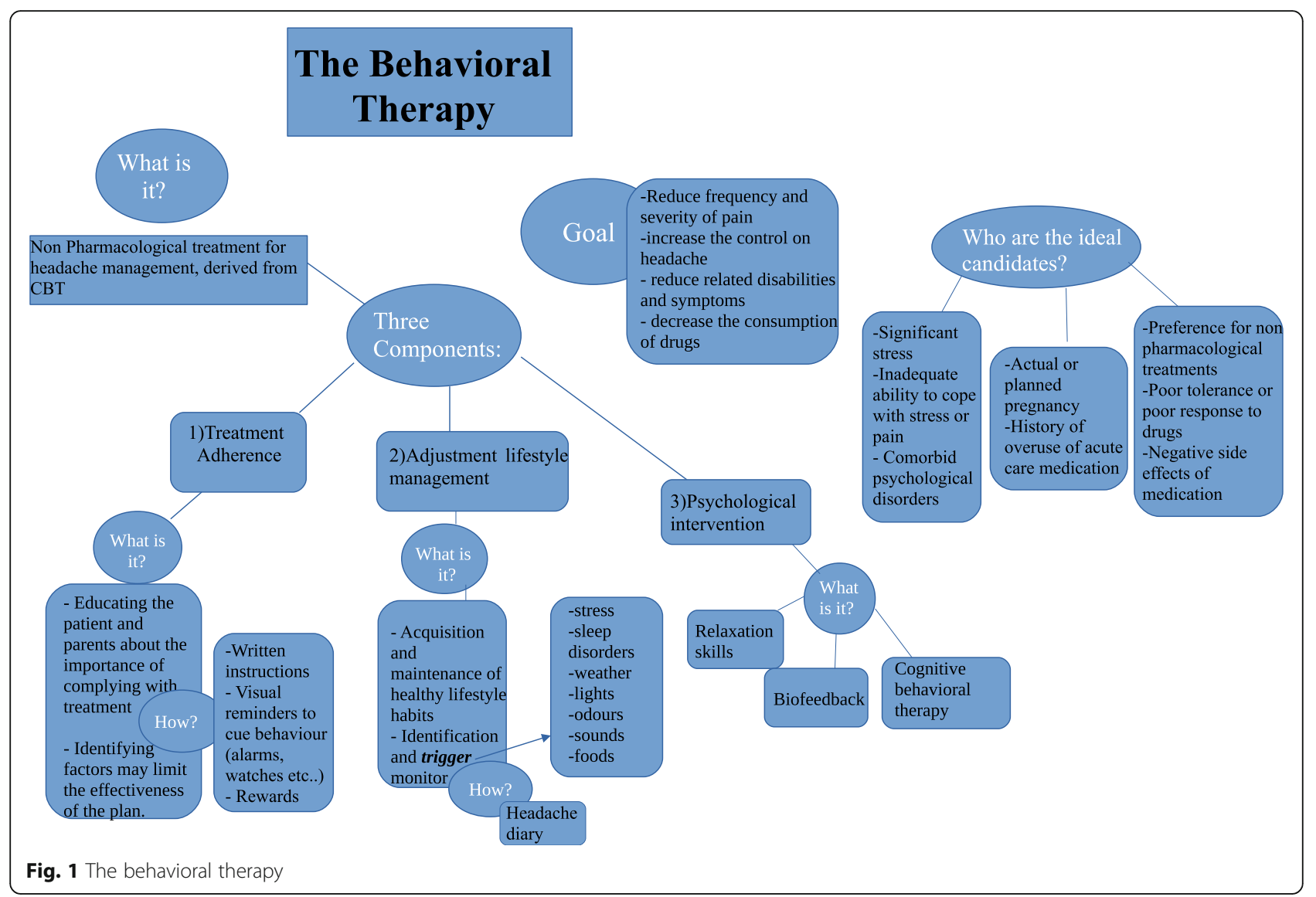

support that non-adherence to treatment is an issue of utmost importance in the treatment of headache; indeed a good adherence to treatment has a positive impact on disease severity, risk of relapse, greater health care utilization, and sub optimal symptom management $[24,25]$. The literature about this topic in children and adolescents is poor: to date a few studies have investigated this factor in pediatric headache [27-30].

Non-adherence to headache treatment is estimated at 50-88 \% among children and adolescence [24, 31]. Treatment non-adherence can affect not only the prognosis of the disorder, with a worsening condition but also the overall health care system with an increased costs and an overuse of the health care system. Indeed non adherence to treatment leads to poor outcomes, which then increase service utilization and health care cost [32]. The factors that may limit the adherence to treatment can be divided in three categories: (1) regimen characteristics (e.g. difficulty of lifestyle changes), (2) disease characteristics (e.g. younger age of onset, frequency and severity of headache attacks), and (3) patient or family characteristics (e.g., premorbid/comorbid behavioral, psychopathology or dysfunctional family) [22, 33]. Factors that can have a positive effect on adherence are positive family functioning, close friends, internal locus of control, treatment with immediate benefits, and a good collaboration between doctor and patient [34]. The identification of needs, anxieties and expectations of the patients and their families regarding the treatment, allows the medical staff to monitor any possible preoccupation and fear, so that the best migraine management approach is administered to improve the quality of life of children and adolescents [35]. Interventions can have an educational, behavioral and clinical focus. Educational strategies provide verbal and written instructions to patients and their parents about the management of headache symptoms and the importance of the proposed treatment [22]. Educating patients can help reduce the helplessness and fear commonly experienced with migraine, enabling them to take control, reduce acute headache pain, and optimize long-term quality of life [36, 37]. Visual reminders to cue behaviour, such as charts for relaxation practice, alarms on watches or phones, self-monitoring, and rewards for treatment compliance are often used to help encourage adherent behaviour [22]. In children and adolescents a useful technique to remember is to pair a new behavior with a behavior that is already well-established in daily routine, such as brushing teeth [34]. Furthermore, a number of emotional and behavioral problems can occur, that 


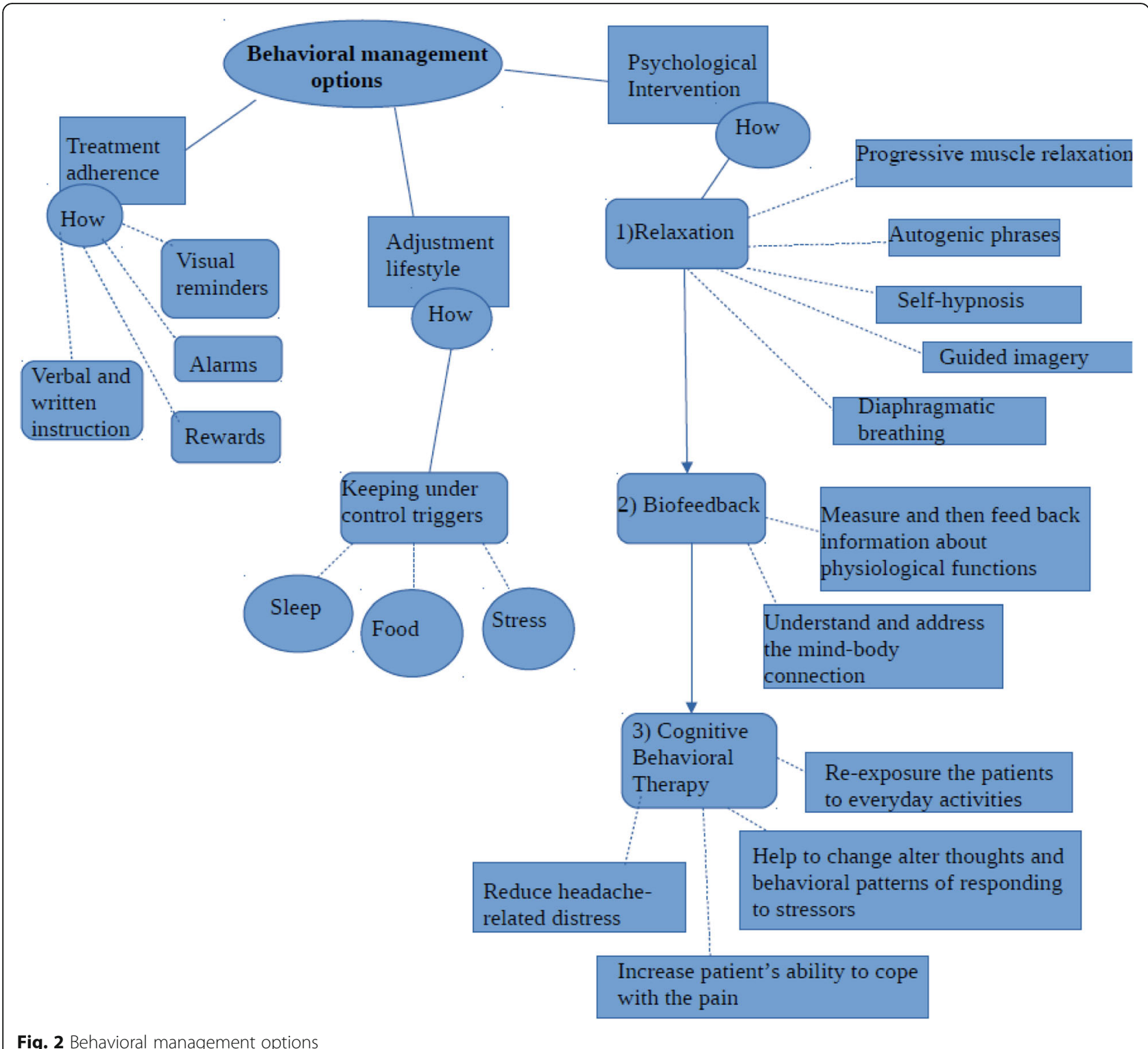

Fig. 2 Behavioral management options

interfere with the success of a treatment. These cases require clinical intervention strategies to modify these behavioural and emotional difficulties. All the obstacles, fears, anxieties and troubles that patients meet along the way, must be identified and addressed in the plan.

\section{Adjustment of lifestyle habits}

Lifestyle interventions are focused on the acquisition and maintenance of healthy lifestyle habits [22]. Clinicians have the task of assisting children and their families in changing lifestyle habits, and of pointing out the importance of this issue. Indeed, lifestyle habits have a great influence on medical outcomes and changing unhealthy habits and behaviours can significantly improve quality of life [38]. There is evidence that unhealthy lifestyle habits are a trigger for childhood headaches [22, 26]. Headache triggers are varied and may have different results at different times, so it can be very difficult to identify them. A headache diary can be a useful way to keep headache attacks under control [39]. Headache triggers often include stress, sleep disorders, weather, lights, odours, sounds and specific foods [40-42].

The most common trigger was stress which was reported by $75.5 \%$ of patients [41]; sources of stress in children and adolescents can include:

- school: new school or new teacher, tests and exams, bullying, learning disabilities 
- family: very permissive or very strict parents, a new brother or sister, divorce, death of a family member.

- friends: very few friends, peers make fun of him/her.

Many studies show that there is a clear association between headache and sleep disorders [43, 44].

In sample of Neut D. et al., lack of sleep was reported by $69.6 \%$ of patients [41]. Children with headache report more daytime symptoms of sleep disturbance including fatigue, tiredness, and sleepiness [45]. Bruni et al. [46] revealed that keeping a consistent bedtime and waking time, sleeping the same amount of hours every night, ensuring that sleep is continuous without frequent awakening, and restricting the intake of food and fluids prior to sleeping reduced headache frequency and duration.

Another commonly reported headache trigger in children are fluctuations in weather [40, 47]. Connelly et al. [47], found that relative humidity and presence of precipitation were significantly predictive of new headache onset in children and adolescents.

An abnormal sensitivity to or intolerance of light (photophobia) is reported as a trigger by $52.9 \%$ of children and adolescents with headache [41]; a hypersensitivity to odours (osmophobia) by $55 \%$ and an intolerance or hypersensitivity to sound (phonophobia) by $47 \%$ [48]. These diseases affect mainly children with diagnosis of migraine than tension-type headache, so the presence of these factors can be a supportive diagnostic criterion for the differential diagnosis between migraine and tension-type headache [49].

Some foods can be a trigger for headache attacks, maybe because they activate biochemical mechanisms involved in headache disorder. For example, chocolate was reported by $11.8 \%$ and cheese by $3.9 \%$ [41]. On the other hand, the consumption of other food and drink items was found to be beneficial [50]. Nutraceuticals, for instance, can be effective in treating migraines in children and adolescents [51]. Moreover, magnesium, riboflavin, coenzyme Q10, the herbal extracts of butterbur, feverfew, and ginkolide B have all been suggested as preventatives for migraine [52-55]. Research has indicate that magnesium in migraine patients is significantly lower than the normal population, and is related to the frequency of migraine attacks, supporting the use of magnesium in prevention and treatment of migraine [56]. Foods that are high in magnesium include beans, fish, walnuts, rice, almonds, dark leafy greens, seeds, whole grains, avocados, yoghurt, bananas and dark chocolate. Riboflavin (B2), acting on mitochondrial metabolism, is shown to be effective in the treatment of migraines, even if more research is needed in children [57]. Coenzyme Q10 has demonstrated the potential to modify inflammatory changes and alteration of mitochondrial function that may occur during recurrent headaches [58]; foods that are also high in Q10 include cereals, nuts and vegetables. Combinations of ginko, coenzyme Q10, riboflavin, and magnesium have been studied in children and adolescents with migraine with positive outcomes $[52,59]$.

Researchers at the City of London Migraine Clinic found that feverfew a traditional medicinal herb, eliminates about two-thirds of migraines in a selected group of adult headache patients, which is similar to the effectiveness of most migraine drugs, [60] but to date there are no trials that indicate the safety or efficacy of feverfew for pediatric headache [61].

Oxidative stress, a disturbance in the balance between the production of free radicals and antioxidant defenses [62], plays a role in the development of paediatric migraine [63], so it is important finding new therapeutic factors with antioxidant properties for treatment of headache.

So there is evidence that lifestyle changes such as healthy sleeping habits, good hygiene, diet free of food additives are associated with a significantly lower frequency of migraine attacks and shorter disease duration for children and adolescents with migraine [64].

\section{Psychological intervention}

Psychological treatments are essential elements of the multidisciplinary, bio-psychosocial management of primary headache disorders, particularly for those with frequent or chronic headache, a high level of headache-related disability, medication overuse, or comorbid psychiatric symptoms [65]. In children and adolescents, headache is commonly associated with several psychiatric comorbidities, in particular depression, anxiety and attention-deficit/hyperactivity disorder [5]. Teaching relaxation techniques, stress reduction, increasing physical activity, and other psychological interventions should be considered standard management options for children with headache and other comorbidities [36]. Self-regulation strategies, such as relaxation and biofeedback, as well as cognitive behavior therapies are reported as the most commonly used behavioral treatments for headache $[22,66]$. These treatments emphasize the active involvement of patients and they aim to change dysfunctional thoughts and maladaptive behaviors, in order to facilitate the use of effective strategies for coping with pain, and to improve headache symptoms [67].

Active involvement of patients can lead to increased confidence in abilities to prevent and manage headaches $[22,68]$, which in turn can lead to less headache-related disability [22,69]. In management of primary headache, psychological treatments include [65]:

- Relaxation skills;

- Biofeedback

- Cognitive behavioral therapy.

Relaxation skills are used to decrease headache by enabling patients to modify their own headache-related 
physiological responses and decrease sympathetic arousal $[22,70]$. Techniques to reduce tension include: progressive muscle relaxation (PMR), autogenic phrases, self-hypnosis, guided imagery (GI), and diaphragmatic breathing [71] (Table 1). These techniques have been shown to be as effective as pharmacological treatment in child, adolescent and adult, improving the frequency, intensity, and duration of headache $[72,73]$.

Biofeedback refers to the use of electronic or electromechanical tools to measure and then feed back information about physiological functions and it is useful in paediatric headache to understanding and addressing the mind-body connection [22, 74]. Multiple published studies have suggested that biofeedback is effective in reducing the frequency and severity of headaches, often allowing patients to decrease their dependence on medication [75].

Cognitive behavioral therapy is a treatment that targets behaviours, emotions, and cognitions that trigger or aggravate headaches [66]. CBT consists mainly of cognitive and behavioral techniques and it helps the patient alter thoughts, interpretations of events, assumptions, and typical behavioral patterns of responding to stressors or events, increasing patient's ability to cope with the pain and to reduce headache-related distress [22]. Cognitivebehavioral techniques, in particular, have been found to reduce the intensity and frequency of headache in children and adolescents [76]. It is proposed that these competencies could contribute to the successful long-term prevention of an adverse course of headache into adulthood [77].

\section{The Efficacy of Behavioral Intervention in children and adolescence with headache}

Behavioral interventions provide a treatment option that can enhance or if necessary, replace pharmacotherapy. The combination of both pharmacological and nonpharmacological treatment has been shown to be superior to each individually, and appears to maximize longterm therapeutic benefit of treatment [78, 79]. During the past several decades, it has become clear that all mental processes derive from mechanisms of the brain [80]. This means that any change in our psychological processes is reflected by changes in the functions or structures of the brain and there is clear evidence that

Table 1 Relaxation skills

\begin{tabular}{ll}
\hline Relaxation skill & What is it? \\
\hline $\begin{array}{l}\text { Progressive muscle relaxation } \\
\text { Autogenic phrases }\end{array}$ & $\begin{array}{l}\text { Series of relaxation exercises } \\
\text { Phrases focused on several parts of the } \\
\text { body (e.g. "my arms are heavy") } \\
\text { Self-hypnosis }\end{array}$ \\
Puided imagery & $\begin{array}{l}\text { Patients must focus on image of peace } \\
\text { and serenity }\end{array}$ \\
Diaphragmatic breathing & Patients learn to breath using diaphragm \\
\hline
\end{tabular}

our subjective experiences affect the brain [81]. Psychotherapy provides the learning of new alternative ways of thinking and behaving. This learning can bring change in the brain by altering the strength of synaptic interactions between neurons, thereby leading to real morphological changes in the neurons themselves and generating new conditions in the brain [82, 83].

Neuroimaging studies have found that psychotherapy has measurable effects on the central nervous system: psychotherapy may modify brain function and metabolism in specific brain areas $[84,85]$. Many psychotherapies attempt to enhance patients' problem-solving capacities, self-representation, and regulation of affective states [86]. The brain areas involved in these functions are the dorsolateral prefrontal cortex, the ventral anterior cingulate cortex, the dorsal anterior cingulate cortex, the ventral and dorsal sub-regions of the medial prefrontal cortex, the posterior cingulate cortex, the precuneus, the insular cortex, the amygdala, and the ventrolateral prefrontal cortex [87]. About twenty studies have been published on brain effects of psychological treatments for obsessive compulsive disorder, anxiety disorder (e.g. panic disorder and social phobia), schizophrenia and depression. In this way it is possible to treat the comorbidities present in subjects with headache and thereby improve their quality of life.

Children with chronic physical illness are significantly more likely to develop common psychiatric symptoms than otherwise healthy children [88], and high levels of psychological comorbidity [5] has led to migraine becoming more commonly viewed as a bio-psychosocial condition, influenced by cognitive, emotional and environmental factors, as well as biological [89].

A recent systematic review about psychological interventions for mental health disorders in children with chronic physical illness, in fact, shows that children may benefit from cognitive behavioral interventions for depression and anxiety in the context of a comorbid chronic physical health problem [88].

A recent meta-analysis showed that psychological therapies can significantly reduce pain and disability in children and adolescents with chronic pain, and in particular headache pain [90]. Reviews using CBT on children, adolescents and adult headache patients showed reduction in migraine and tension-type headache attacks in a pre-/post-treatment for intensity, frequency, and duration of headache, significantly superior to control conditions [11, 66, 91-93].

Power et al. [12] carried out a study to determine the benefits of CBT in children and adolescents (aged 10-17) with chronic migraine, when combined with amitriptyline versus headache education plus amitriptyline. They find that, in children and adolescents with chronic migraine, the use of CBT plus amitriptyline is associated with greater 
reductions in days with headache and migraine-related disability compared with use of headache education plus amitriptyline. These findings support the efficacy of CBT in the treatment of chronic migraine in children and adolescents. Chen YZ et al. [94] investigate the preventive effect of behavioral therapy plus flunarizine in children with migraine, and report that preventive treatment of behavioral therapy plus oral flunarizine had better clinical efficacy than oral flunarizine alone, in children with migraine.

Relaxation techniques, including PMR, autogenic phrases, self-hypnosis, GI, and diaphragmatic breathing has been shown to be an effective therapeutic approach for the management of headaches in children and adolescents [27, 95-99]. Trautmann et al. [100] found that relaxation, biofeedback, and CBT are highly effective in treating headache symptoms, both in frequency and severity. Relaxation or biofeedback alone obtain improvement in about $50 \%$; when combined about $60 \%$ improvement was seen [101]. With CBT and biofeedback, improvement in children with migraine reaches $75 \%$ [102]. Blume et al., found a positive response to biofeedback in $58 \%$ and a 43 $\%$ reduction in headache days with biofeedback therapy in children and adolescents with headache [103].

Meta-analytic findings of Palermo et al. demonstrated a large positive effect of psychological intervention on pain reduction at immediate post-treatment and follow-up in youth with headache. It would appear that cognitivebehavioral therapy, relaxation therapy, and biofeedback all produced improvement in pain relief [104].

Fisher et al. [105] show the efficacy also of psychological therapies delivered remotely, compared to waiting-list, treatment-as-usual, or active control treatments, for the management of chronic pain in children and adolescents. Psychological therapy delivered remotely confirms benefit in reducing the intensity or severity of pain in children.

Penzien et al. report [19] the following recommendations pertaining to behavioral interventions for migraine (as they have been outlined by the US Headache Consortium) [106]: (1) relaxation training, thermal biofeedback combined with relaxation training, electromyographic biofeedback, and cognitive behavioral therapy are treatment options for prevention of migraine (grade A evidence); and (2) behavioral therapy may be combined with preventive drug therapy to achieve added clinical improvement for migraine (grade B evidence).

Further studies are needed to point out the exact mechanisms of behavioral treatments [107] in children and adolescents with primary headache, which are likely multifactorial.

\section{Limitations}

Behavioral therapy like other forms of headache management is imperfect [108], and some issues make it inadequate for some people (Table 2 Strengths and limitations):
1) Behavioral approaches give us an idea of how individuals react to specific life situations, but patterns of behaviour may vary over the course of an individual's life [108].

2) Although behavioral treatment is considered a shortterm therapy, it takes time to change same behaviours and replace negative behaviours with positive ones. Parents and teachers may find this frustrating.

3) Behavioral therapy has focused on the development and study of specific effective techniques to address different clinical situations; however, it sometimes does not always take into account individual differences that imply that these methods cannot be applied in the same way to all subjects [108].

4) Behavioral therapy teaches individuals some skills for coping with the problems (cognitive restructuring, problem solving, relaxation), but teaching parents skills to work more effectively with their children can result in a poor compliance. A working relationship between the patient and therapist is an essential part of any psychotherapy and is crucial for patient's improvement [109].

5) In behavioral interventions the emphasis is on the "here and now" [110], but sometimes it is necessary to go back in time and explore the origin of the disorder.

6) Behavioral therapists must recognize that they have become embedded in a relationship with the patient, so they must maintain a sense of awareness and control over their own emotional reactions to the patient's behaviour [111].

7) CBT may not be effective for people with severe mental disorders or for those with learning difficulties. The focus of CBT is always on patients and their capacity to bring change to themselves [112].

Table 2 Strengths and limitations

\begin{tabular}{|c|c|}
\hline Strengths & Limitations \\
\hline Cost saving & $\begin{array}{l}\text { It takes time to change same } \\
\text { behaviors, so parents and teachers } \\
\text { may find this frustrating. }\end{array}$ \\
\hline Ensure Compliance & $\begin{array}{l}\text { Teach parents how work more } \\
\text { effectively with their children can } \\
\text { result in a poor compliance }\end{array}$ \\
\hline $\begin{array}{l}\text { Maximize long term therapeutic } \\
\text { benefit }\end{array}$ & The focus is "here and now" \\
\hline $\begin{array}{l}\text { No negative side effects of } \\
\text { medications }\end{array}$ & $\begin{array}{l}\text { Therapist must maintain a sense } \\
\text { of control and awareness }\end{array}$ \\
\hline $\begin{array}{l}\text { Learning of new alternative ways } \\
\text { of thinking and behaving }\end{array}$ & $\begin{array}{l}\text { Patterns of behavior may change } \\
\text { over the course of life }\end{array}$ \\
\hline $\begin{array}{l}\text { Reduction of headache severity } \\
\text { and frequency }\end{array}$ & $\begin{array}{l}\text { It is not effective for people with } \\
\text { severe mental disorder }\end{array}$ \\
\hline Reduce pain and disability & $\begin{array}{l}\text { It does not always take into } \\
\text { account individual differences }\end{array}$ \\
\hline
\end{tabular}


Behavioral headache interventions continue to face significant challenges that in part derive from the inability to conduct a truly double blind trial, and from limited availability of behaviourally trained headache clinicians [19, 113]. Rains in his review about the "Behavioral Headache Treatment" [66] has presented a critique of methodological quality of the clinical trials literature, highlighting the strengths and weaknesses in relation to recruitment and selection of patients, sample size and statistical power, the use of a credible control, and the reproducibility of the study interventions in clinical practice. There is a little research on the effectiveness of behavioral headache interventions in children and adolescence and this topic has often been discussed rather than clinically investigated.

\section{Conclusion}

Headache is a common condition among children and adolescents that has a large impact on school and other areas of daily life, and more generally on the quality of life of children and their families. Lacking proper care, many children will continue to experience headaches into adulthood. These considerations point to the importance of prompt, effective, and early intervention for paediatric headache [4].

Multidisciplinary treatment is an effective strategy for children and adolescents and shows improvement in multiple measures of outcome, including frequency and severity of headache and number of school days missed because of headache. Behavioral therapy is very useful to such an intervention [114]. Attention to the effects of headache, to needs and fears of children and adolescents, and to factors that may limit the effectiveness of the therapy, is an important part of treatment.

Behavioral therapy may reduce the need for medication, and help maintain effects over the long term. There is evidence that psychological treatments are effective in reducing pain intensity in children and adolescents with headache, and that therapies such as relaxation and cognitive behavioral therapy may have lasting effect in improving mood and reducing pain for chronic headache [115]. The application of behavioral therapy in the management of headache in children and adolescents is an effective alternative to drugs without the problematic and dangerous side effects of pharmacological treatments and the cost savings of not having to purchase prescription or over-the-counter medications [116, 117]. Clinicians should inquire about behavioral therapy and other non pharmacological treatments for migraine, in order to plan an integrative approach, especially in children and adolescents with headache.

\section{Acknowledgements}

The authors thank Miss Felicity Williams for her thorough English language editing.

\section{Funding}

This research received no specific grant from any funding agency in the public, commercial, or non-profit sectors.

\section{Authors' contributions}

NF and VG conceived and designed the study. RC, PV, MA were responsible for critical revision of this manuscript. NF, RC, PV, MA, DM and VG were responsible for data acquisition. All authors approved the final version of this manuscript.

\section{Competing interests}

The authors declare that they have no competing interests.

\section{Author details}

${ }^{1}$ Department of Pediatrics and Child and Adolescent Neuropsychiatry, Sapienza University of Rome, Via dei Sabelli, 108, 00185 Rome, Italy.

${ }^{2}$ Department of Dynamic and Clinical Psychology, Sapienza University of Rome, Rome, Italy. ${ }^{3}$ Department of Computer, Control and Management Engineering Antonio Ruberti, Sapienza University of Rome, Rome, Italy. ${ }^{4}$ Glia Institute, Ribeirão Preto, São Paulo, Brazil.

Received: 2 July 2016 Accepted: 20 August 2016

Published online: 05 September 2016

\section{References}

1. Abu-Arafeh I (2014) Diagnosis and management of headache in children and adolescents. Prog Neurol Psychiatry 18(4):16-20

2. Hershey AD (2012) Pediatric headache: update on recent research. Headache 52(2):327-332

3. Lipton RB, Bigal ME (2007) Ten lessons in the epidemiology of migraine. Headache 47(1):S2-S9

4. Powers SW, Andrasik F (2005) Biobehavioral treatment, disability, and psychological effects of pediatric headache. Pediatr Ann 34:461-465

5. Bellini B, Arruda M, Cescut A, Saulle C, Persico A, Carotenuto M, Gatta M, Nacinovich R, Piazza FP, Termine C, Tozzi E, Lucchese F, Guidetti V (2013) Headache and comorbidity in children and adolescents. J Headache Pain 14:79

6. Blaauw BA, Dyb G, Hagen $K$, Holmen $T L$, Linde $M$, Wentzel-Larsen $T$, Zwart JA (2015) The relationship of anxiety, depression and behavioral problems with recurrent headache in late adolescence - a Young-HUNT follow-up study. J Headache Pain 16:10

7. Pompili M, Serafini G, Di Cosimo D, Dominici G, Innamorati M, Lester D, Forte A, Girardi N, De Filippis S, Tatarelli R, Martelletti P (2010) Psychiatric comorbidity and suicide risk in patients with chronic migraine. Neuropsychiatr Dis Treat 6:81-91

8. Serafini G, Pompili M, Innamorati M, Gentile G, Borro M, Lamis DA, Lala N, Negro A, Simmaco M, Girardi P, Martelletti P (2012) Gene variants with suicidal risk in a sample of subjects with chronic migraine and affective temperamental dysregulation. Eur Rev Med Pharmacol Sci 16(10):1389-1398

9. Serafini G, Pompili M, Innamorati M, Negro A, Fiorillo M, Lamis DA, Erbuto D, Marsibilio F, Romano A, Amore M, D'Alonzo L, Bozzao A, Girardi P, Martelletti $P$ (2012) White matter hyperintensities and self-reported depression in a sample of patients with chronic headache. J Headache Pain 13(8):661-667

10. Piccinini M, Vieno A, Santinello M (2011) Use of medicines and lifestyles among Italian adolescents. Epidemiol Prev 35(3-4):222-228

11. Christiansen S, Jürgens TP, Klinger R (2015) Outpatient Combined Group and Individual Cognitive-Behavioral Treatment for Patients With Migraine and Tension-Type Headache in a Routine Clinical Setting. Headache 55(8):1072-1091

12. Powers SW, Kashikar-Zuck SM, Allen JR, LeCates SL, Slater SK, Zafar M, Kabbouche MA, O'Brien HL, Shenk CE, Rausch JR, Hershey AD (2013) Cognitive Behavioral Therapy Plus Amitriptyline for Chronic Migraine in Children and Adolescents A Randomized Clinical Trial. Jama 310(24):2622-2630 
13. Mazzotta G, Gallai B, Mattioni A, Floridi F, Foti F, Allegretti M, D'Angelo R (2005) Cost assessment of headache in childhood and adolescence: preliminary data. J Headache Pain 6(4):281-283

14. Mauskop A (2012) Nonmedication, alternative, and complementary treatments for migraine. Continuum (Minneap Minn) 18(4):796-806

15. Weeks RE (2013) Application of behavioral therapies in adult and adolescent patients with chronic migraine. Neurol Sci 34(1):S11-S17

16. Basler HD, Franz C, Kröner-Herwig B, Rehfisch HP (eds) (2004) Psychologische Schmerztherapie. Springer, Berlin

17. Damen L, Bruijn J, Koes BW, Berger MY, Passchier J, Verhagen AP (2006) Prophylactic treatment of migraine in children. Part 1. A systematic review of non-pharmacological trials. Cephalalgia 26(4):373-383

18. Campbell JK, Penzien D, Wall EM (2000) Evidence-based guidelines for migraine headache: behavioral and physical treatments. Neurology [serial online] http://tools.aan.com/professionals/practice/pdfs/gl0089.pdf. Org. Accessed 15 May 2016

19. Penzien DB, Irby MB, Smitherman TA, Rains JC, Houle TT (2015) Wellestablished and empirically supported behavioral treatments for migraine. Curr Pain Headache Rep 19:34

20. Robbins M, Grosberg BM, Lipton R (2013) Headache. In: Gross RA, Mink JW (eds) Neurology in Practice. Wiley-Blackwell, NY, USA. p 336

21. Rathier L, Roth J (2015) A Biobehavioral Approach to Headache Management. In: Roth J (Ed) Headache Disorders, vol 26. Rhode Island Med J 98(2):26-28

22. Kabbouche MA, Gilman DK (2008) Management of migraine in adolescents. Neuropsychiatr Dis Treat 4(3):535-548

23. Powers SW, Gilman DK, Hershey AD (2006) Suggestions for a biopsychosocial approach to treating children and adolescents who present with headache. Headache 46(3):S149-S150

24. Ramsey RR, Ryan JL, Hershey AD, Powers SW, Aylward BS, Hommel KA (2014) Treatment Adherence in Patients With Headache: A Systematic Review. Headache 54:795-816

25. Rapoff MA (2010) Adherence to Pediatric Medical Regimens, 2nd edn Springer, New York

26. Winner P, Migraine (2009) Diagnosis and Treatment. In: Hershey AD, Powers SW, Winner P, Kabbouche MA (eds), Pediatric Headaches in Clinical Practice. John Wiley \& Sons, Oxford. p 83-95

27. Grazzi L, Andrasik F, Usai S, D’Amico D, Bussone G (2004) Pharmacological behavioural treatment for children and adolescents with tension-type headache: Preliminary data. Neurol Sci 25(3):S270-S271

28. Andrasik F, Grazzi L, Usai S, Bussone G (2007) Pharmacological treatment compared to behavioural treatment for juvenile tension-type headache: Results at two-year follow-up. Neurol Sci 28(2):S235-S238

29. Allen KD, McKeen LR (1991) Home-based multicomponent treatment of pediatric migraine. Headache 31:467-472

30. Engel JM (1993) Children's compliance with progressive relaxation procedures for improving headache control. OTJR (Thorofare N J) 13:19-230

31. Drotar D (ed) (2000) Promoting Adherence to Medical Treatment in Chronic Childhood IIIness: Concepts, Methods, and Interventions. Lawrence Eribaum Associates, Mahwah

32. luga AO, McGuire MJ (2014) Adherence and health care costs. Risk Manag Healthc Policy 7:35-44

33. LaGreca AM, Schuman WB (1995) Adherence to prescribed medica regimens. In: Roberts MC (ed) Handbook of Pediatric Psychology. Guilford, New York, pp 55-83

34. Taddeo D, Egedy M, Frappier JY (2008) Adherence to treatment in adolescents. Paediatr Child Health 13(1):19-24

35. Becker WJ, Gladstone JP, Aube M (2007) Migraine prevalence, diagnosis and disability. Can J Neurol Sci 34(4):S3-S9

36. Craddock L, Lynne DR (2012) Pediatric migraine teaching for families. J Spec Pediatr Nurs 17(2):98-107

37. Antonaci F, Sances G, Guaschino E, De Cillis I, Bono G, Nappi G (2008) Meeting patient expectations in migraine treatment: What are the key endpoints? J Headache Pain 9:207-213

38. Labos C (2015) Lifestyle Interventions: The Best Medicine You're Not Using http://www.medscape.com/viewarticle/843028. Accessed 17 May 2016

39. Zebenholzer K, Frantal S, Pablik E, Lieba-Samal D, Salhofer-Polanyi S, Wöber-Bingöl C., Wöber C (2016) Reliability of assessing lifestyle and trigger factors in patients with migraine - findings from the PAMINA study. Eur J Neurol 23(1):120-126

40. Chakravarty A, Mukherjee A, Roy D (2009) Trigger factors in childhood migraine: a clinic-based study from eastern India. J Headache Pain 10(5):375-380
41. Neut D, Fily A, Cuvellier JC, Vallée L (2012) The prevalence of triggers in paediatric migraine: a questionnaire study in 102 children and adolescents. $J$ Headache Pain 13(1):61-65

42. Fraga MD, Pinho RS, Andreoni S, Vitalle MS, Fisberg M, Peres MF, Vilanova LC, Masruha MR (2013) Trigger factors mainly from the environmental type are reported by adolescents with migraine. Arq Neuropsiquiatr 71(5):290-293

43. Dosi C, Figura M, Ferri R, Bruni O (2015) Sleep and Headache. Semin Pediatr Neurol 22(2):105-112

44. Freedom T (2015) Headaches and sleep disorders. Dis Mon 61(6):240-248

45. Jennum P, Jensen R (2002) Sleep and headache. Sleep Med Rev 6(6):471-479

46. Bruni O, Galli F, Guidetti V (1999) Sleep hygiene and migraine in children and adolescents. Cephalalgia 19(25):57-59

47. Connelly M, Miller T, Gerry G, Bickel J (2010) Electronic momentary assessment of weather changes as a trigger of headaches in children. Headache 50(5):779-789

48. Powers SW, Hershey AD, Coffey CS, Chamberlin LA, Ecklund DJ, Sullivan SM, Klingner EA, Yankey JW, Kashikar-Zuck S, Korbee LL, Costigan ML, Riss HH, Porter LL (2016) The Childhood and Adolescent Migraine Prevention (CHAMP) Study: A Report on Baseline Characteristics of Participants. Headache doi: 10.1111/head.12810 [Epub ahead of print]

49. Corletto E, Dal Zotto L, Resos A, Tripoli E, Zanchin G, Bulfoni C, Battistella PA (2008) Osmophobia in juvenile primary headaches. Cephalalgia 28(8):825-831

50. Connelly M, Bickel J (2011) An electronic daily diary process study of stress and health behavior triggers of primary headaches in children. J Pediatr Psychol 36(8):852-862

51. Esposito M, Ruberto M, Pascotto A, Carotenuto M (2012) Nutraceutical preparations in childhood migraine prophylaxis: effects on headache outcomes including disability and behaviour. Neurol Sci 33(6):1365-1368

52. Jacobs H, Gladstein J (2012) Pediatric headache: a clinical review. Headache 52(2):333-339

53. Menon S, Lea RA, Ingle S, Sutherland M, Wee S, Haupt LM, Palmer M, Griffiths LR (2015) Effects of dietary folate intake on migraine disability and frequency. Headache 55(2):301-309

54. Cayir A, Turan Ml, Tan H (2014) Effect of vitamin D therapy in addition to amitriptyline on migraine attacks in pediatric patients. Braz J Med Biol Res 47(4):349-354

55. Talebi M, Savadi-Oskouei D, Farhoudi M, Mohammadzade S, Ghaemmaghamihezaveh S, Hasani A, Hamdi A (2011) Relation between serum magnesium level and migraine attacks. Neurosciences (Riyadh) 16(4):320-323

56. Patniyot IR, Gelfand AA (2016) Acute Treatment Therapies for Pediatric Migraine: A Qualitative Systematic Review. Headache Jan 56(1):49-70

57. O'Brien HL, Hershey AD (2010) Vitamins and paediatric migraine: Riboflavin as a preventative medication. Cephalalgia 30(12):1417-1418

58. O'Brien HL, Kabbouche MA, Kacperski J, Hershey AD (2015) Treatment of Pediatric Migraine. Curr Treat Options Neurol 17:1

59. Usai S, Grazzi L, Bussone G (2011) Ginkolide B as migraine preventative treatment in young age; results at 1-year follow-up. Neurol Sci 32(1):S197-S199

60. Sun-Edelstein C, Mauskop A (2009) Foods and supplements in the management of migraine headaches. Clin J Pain 25(5):446-452

61. Tepper SJ (2008) Complementary and alternative treatments for childhood headaches. Curr Pain Headache Rep 12(5):379-383

62. Betteridge DJ (2000) What is oxidative stress? Metabolism 49(2 Suppl 1):3-8

63. Boćkowski L, Sobaniec W, Kułak W, Smigielska-Kuzia J (2008) Serum and intraerythrocyte antioxidant enzymes and lipid peroxides in children with migraine. J Pharmacol Rep 60(4):542-548

64. Eidlitz-Markus T, Haimi-Cohen Y, Steier D, Zeharia A (2010) Effectiveness of nonpharmacologic treatment for migraine in young children. Headache 50(2):219-223

65. Sieberg CB, Huguet A, von Baeyer CL, Seshia S (2012) Psychological interventions for headache in children and adolescents. Can J Neurol Sci 39(1):26-34

66. Rains JC, Penzien DB, McCrory DC, Gray RN (2005) Behavioral headache treatment: history, review of the empirical literature, and methodological critique. Headache 45(2):S92-S109

67. Ehde MD, Dillworth MT, Turner JA (2014) Cognitive-Behavioral Therapy for Individuals With Chronic Pain. Am Psychol Assoc 69(2):153-166 
68. Andrasik F (2003) Behavioral treatment approaches to chronic headache Neurol Sci 24(2):S80-S85

69. French DJ, Holroyd KA, Pinell C, Malinoski PT, O'Donnell F, Hill KR (2000) Perceived self-efficacy and headache-related disability. Headache 40(8):647-656

70. Penzien DB, Taylor FR (2014) Headache toolbox. Behavioral and other nonpharmacologic treatments for headache. Headache 54(5):955-956

71. Chiappedi M, Mensi MM, Termine C, Balottin U (2016) Psychological Therapy in Adolescents with Chronic Daily Headache. Curr Pain Headache Rep 20(1):3

72. Sieberg RGJ, McGrath PJ (1996) Psychological treatments for migraine. Biomed Pharmacother 50(2):58-63

73. Engel JM, Rapoff MA, Pressman AR (1992) Long-term follow-up of relaxation training for pediatric headache disorders. Headache 32(3):152-156

74. Powers SW, Hershey AD (2002) Biofeedback for childhood migraine. In: Maria BL (ed) Current Management in Child Neurology. BC Decker, Inc, Hamilton, pp 83-85

75. Mullally WJ, Hall K, Goldstein R (2009) Efficacy of biofeedback in the treatment of migraine and tension type headaches. Pain Physician 12(6):1005-1011

76. Balottin U, Ferri M, Racca M, Rossi M, Rossi G, Beghi E, Chiappedi M, Termine C (2014) Psychotherapy versus usual care in pediatric migraine and tension-type headache: a single-blind controlled pilot study. Ital J Pediatr 40:6

77. Kröner-Herwig B (2014) Headache in children and adolescents. Epidemiology, biopsychosocial correlates, and psychological treatment approaches. Bundesgesundheitsblatt Gesundheitsforschung Gesundheitsschutz 57(8):928-934

78. Holroyd KA, Cottrell CK, O'Donnell FJ, Cordingley GE, Drew JB, Carlson BW, Himawan L (2010) Effect of preventive (beta blocker) treatment, behavioural migraine management, or their combination on outcomes of optimised acute treatment in frequent migraine: randomised controlled trial. BMJ 341:C4871

79. Levine M (2008) Comprehensive Review of Headache Medicine, Oxford University Press. p 336

80. Kandel ER (1998) A new intellectual framework for psychiatry. J Psychiatry 155(4):457-469

81. Gabbard GO (2000) A neurobiologically informed perspective on psychotherapy. Br J Psychiatry 177:117-122

82. Mayford M, Siegelbaum SA, Kandel ER (2012) Synapses and memory storage. Cold Spring Harb Perspect Biol. 4(6)

83. Beauregard M (2014) Functional neuroimaging studies of the effects of psychotherapy. Dialogues Clin Neurosci 16(1):75-81

84. Janiri L, Guglielmo R, Bruschi A (2009) Psicoterapia e neuroscienze: l'integrazione possibile. Modelli per la mente, 2(2):7-13

85. Mundo E (2006) Neurobiology of dynamic psychotherapy: an integration possible? J Am Acad Psychoanal Dyn Psychiatry 34(4):679-691

86. Karlsson H (2011) How Psychotherapy Changes the Brain. Psychiatric Times 28(8). http://www.psychiatrictimes.com/psychotherapy/how-psychotherapychanges-brain.Accessed 27 April 2016

87. Frewen PA, Dozois DJ, Lanius RA (2008) Neuroimaging studies of psychological interventions for mood and anxiety disorders: empirical and methodological review. Clin Psychol Rev 28(2):228-246

88. Bennett S, Shafran R, Coughtrey A, Walker S, Heyman I (2015) Psychological interventions for mental health disorders in children with chronic physical illness: a systematic review. Arch Dis Child 100:308-316

89. Cousins S, Ridsdale L, Goldstein LH, Noble AJ, Moorey S, Seed P (2015) A pilot study of cognitive behavioural therapy and relaxation for migraine headache: a randomised controlled trial. J Neurol 262(12):2764-2772

90. Fisher E, Heathcote L, Palermo TM, Williams AC, Lau J, Eccleston C (2014) Systematic Review and Meta-Analysis of Psychological Therapies for Children With Chronic Pain. J Pediatr Psychol 39(8):763-782

91. Holroyd KA (2002) Assessment and psychological management of recurrent headache disorders. J Consult Clin Psych 70:656-677

92. Penzien DB, Rains JC, Andrasik F (2002) Behavioral management of recurrent headache: Three decades of experience and empiricism. Appl Psychophysiol Biofeedback 27:163-181

93. Andrasik F (2007) What does the evidence show? Efficacy of behavioural treatments for recurrent headaches in adults. Neurol Sci 28:70-77

94. Chen YZ, Li N, Zhou KY (2014) Preventive effect of behavioral therapy plus flunarizine in children with migraine. Zhongguo Dang Dai Er Ke Za Zhi 16(11):1105-1108
95. Eccleston C, Yorke L, Morley S, Williams AC, Mastroyannopoulou K (2003) Psychological therapies for the management of chronic and recurrent pain in children and adolescents. Cochrane Database Syst Rev 1 , CD003968

96. Kohen DP (2010) Long-term follow-up of self-hypnosis training for recurrent headaches: what the children say. Int J Clin Exp Hypn 58(4):417-432

97. Sierpina V, Astin J, Giordano J (2007) Mind-body therapies for headache. Am Fam Physician 76(10):1518-1522

98. Olness K, MacDonald JT, Uden DL (1987) Comparison of self-hypnosis and propranolol in the treatment of juvenile classic migraine. Pediatrics 79(4):593-597

99. Kohen DP (2011) Chronic daily headache: helping adolescents help themselves with self-hypnosis. Am J Clin Hypn 54(1):32-46

100. Trautmann E, Lackschewitz H, Kröner-Herwig B (2006) Psychological treatment of recurrent headache in children and adolescents-a metaanalysis. Cephalalgia 26(12):1411-1426

101. Kropp P, Meyer B, Landgraf M, Ruscheweyh R, Ebinger F, Straube A (2013) Headache in children: update on biobehavioral treatments. Neuropediatrics 44(1):20-24

102. Andrasik F (1996) Behavioral management of migraine. Biomed Pharmacother 50(2):52-57

103. Blume HK, Brockman LN, Breuner CC (2012) Biofeedback therapy for pediatric headache: factors associated with response. Headache 52(9):1377-1386

104. Palermo TM, Eccleston C, Lewandowski AS, Williams AC, Morley S (2010) Randomized controlled trials of psychological therapies for management of chronic pain in children and adolescents: an updated meta-analytic review. Pain 148(3):387-397

105. Fisher E, Law E, Palermo TM, Eccleston C (2010) Psychological therapy (remotely delivered) for the management of chronic pain and recurrent pain in Ch and Adol. Cochrane Database System, 2015 combination on outcomes of optimised acute treatment in frequent migraine: randomised controlled trial. BMJ 341:c4871

106. Silberstein SD (2000) Practice parameter: evidence-based guidelines for migraine headache (an evidence-based review) report of the Quality Standards Subcommittee of the American Academy of Neurology. Neurology 55(6):754-762

107. Penzien DB, Irby MB (2014) Insights on treatment mechanisms of cognitivebehavioral migraine therapy. Headache 54(9):1439-1440

108. Goldfriend MR, Castonguay LG (1993) Behavior Therapy: Redefining Strenghts and Limitations. Behav Ther 24:505-S26

109. Wright JH, Davis D (1994) The Therapeutic Relationship in CognitiveBehavioral Therapy: Patient Perceptions and Therapist Responses. Cogn Behav Pract 1:25-45

110. Kropf P, Greene RR (2012) Cognitive and Behavioral Approaches: In Kropf P, Greene RR, Competence: Theoretical Frameworks. Aldine Transaction, Transaction Publishers, New Brunswick, NewJersey, 232 pp

111. Leahy RL (2006) A Relational Approach to Negotiating Alliance Ruptures. In: Leahy RL, Roadblocks in Cognitive-Behavioral Therapy: Transforming Challenges Into Opportunities for Change. Guilford Press, New York. pp 364

112. Kennard J (2014) Benefits and Limitations of Cognitive Behavioral Therapy (CBT) for Treating Anxiety. http://www.healthcentral.com/anxiety/c/4182/ 165578/benefits-limitations-treating/. Accessed 20 May 2016.

113. Rains JC, Penzien DB (2005) Behavioral research and the double-blind placebo-controlled methodology: challenges in applying the biomedical standard to behavioral headache research. Headache 45:479-486

114. Termine C, Ozge A, Antonaci F, Natriashvili S, Guidetti V, Wöber-Bingöl C (2011) Overview of diagnosis and management of paediatric headache. Part II: therapeutic management. J Headache Pain 12(1):25-34

115. Health E-BC, Editorial Office (2013) Clinical Answers: Are nonpharmacological interventions for migraine effective in children and Adolescents. Evid-Based Child Health 8:754-758

116. Grazzi L, D'Amico D, Leone M, Moschiano F, Bussone G (1998) Pharmacological and behavioral treatment of pediatric migraine and tension-type headache. Ital J Neurol Sci 19(2):59-64

117. Kohen DP, Zajac R (2007) Self-hypnosis training for headaches in children and adolescents. J Pediatr 150(6):635-639 